accomplished electrochemically, at sive questionnaire running to seventyabout $-560 \mathrm{mV}$.

These observations are particularly striking since it would place the ironsulphur species detected by $\mathrm{Ke}$ et al. at the strongest reducing level known for a biological electron carrier. So far it is difficult to assess the involvement of all these species in primary $\mathrm{S} 1$ activity especially because of the temperature sensitivity of the iron-sulphur centres with midpoint potentials beyond -560 $\mathrm{mV}$. Bearing this in mind the results indicate that the chemical potential, generated between the primary donor (P700) and primary acceptor of S1 due to the absorption of photon energy, could be at least 0.96 or possibly 1.01 $\mathrm{eV}$.

\section{SPACE RESEARCH}

\section{Observing Sutellites}

from a Correspondent

A Discussion meeting on satellite observations and their use in orbital analysis was held at the Royal Society on November 17 . The meeting, organised by the Optical Tracking Subcommittee of the British National Committee on Space Research, was designed to bring together the volunteer visual observers of artificial satellites, whose observations (some 25,000 per year) are so valuable in determining satellite orbits for subsequent analysis in geophysical research.

The meeting began, appropriately enough, with a talk on the visual appearance of satellites by D. M. Brierley (Royal Radar Establishment, Malvern), who emphasised that non-spherical satellites can suffer great variations in brightness when the solar phase angle is unfavourable. J. A. Pilkington (Scarborough Planetarium) discussed some of the difficulties in finding reliable information for listings of newlylaunched satellites, and some old ones too. Recent geophysical advances resulting from analysis of orbits were described by D. G. King-Hele (Royal Aircraft Establishment, Farnborough): he mentioned the new determination of the Earth's pear-shaped polar section (Nature, 246, 86; 1973), and discussed the evaluation of fifteenth-order harmonics in the geopotential from analysis of orbits at fifteenth-order resonance; good values have now been obtained for harmonics of order 15 and degree 15 , 17, $19 \ldots 27 . \quad$ Next G. E. Perry (Kettering Grammar School), accompanied by a tape recorder, regaled the audience with a medley of interesting radio signals from recent satellites caught during his untiring pursuit of transmissions from satellites.

The observers attending the meeting had previously answered a compreheneight questions, prepared by M. D. Waterman (Elliott Automation, Frimley), who reported some interesting features of the statistics. As might be expected with observations relative to the stars, the results of the survey showed that observational accuracy improves with experience: observers are at their best after more than 10 years' practice. An astonishing contrast to this finding was provided by sightings of the flaming decay of satellites: the regular observers at the meeting had made more than a quarter of a million observations and had scanned the night sky for thousands of hours, yet only one of them had seen a decay; but the minority of the audience who were not regular observers included four defiers of the laws of chance, who had seen a decay. There were further contributions from A. J. G. Moorat (Appleton Laboratory, Slough), on satellite predictions; from G. E. Taylor (Royal Greenwich Observatory), on time standards; from R. D. Eberst (Royal Observatory, Edinburgh), on recent work at Edinbugh; and from J. Hewitt (Ordnance Survey), who gave a very clear description of the techniques for laser tracking of satellites.

\section{EARTHQUAKE PREDICTION}

\section{No Dilatancy}

from our Geomagnetism Correspondent

BECAUSE of bad communications, early Russian work on the changes of seismic velocity associated with earthquakes took a long time to become known in the west, and even more surprisingly in Japan. Thus although as long ago as 1962 Kondratenko and Nersesov (Trudy Inst. Fiz. Zemli, 25, 130; 1962) had reported that the velocity of $P$ waves in the crust increases after moderately large earthquakes in the Tadjikistan region of southern central Asia, this secret apparently remained locked inside the Soviet Union until Savarensky (Tectonophysics, 6, 17; 1968) reviewed the results in English. Moreover, even then the Russian studies were treated with some scepticism. Rikitake (EarthSci. Rev., 4, 245; 1968), for example, argued that the $30 \%$ change in elasticity implied by a reported $15 \%$ change in $P$ wave velocity threw doubt on the validity of the original data.

Nevertheless, the appearance of Savarensky's report, other reports of Russian work, and particularly an article by Semenov (Izv. Acad. Sci. USSR Phys. Solid Earth, 4, 245; 1969) giving details of premonitory seismic velocity changes, inspired United States seismologists to search for similar effects. Semenov had shown that before earthquakes in the magnitude range $3-5$, the velocity ratio $v_{\mathrm{p}} / v_{\mathrm{s}}$ decreased by about $6 \%$ and then increased back to its normal value just before the main shock. A few years later, Aggarwal et al. (Nature, 241, 101; 1973) reported similar results involving decreases in $\nu_{\mathrm{p}} / \nu_{\mathrm{B}}$ of up to $13 \%$ for New York earthquakes in the magnitude range 1-3. But the really important result was obtained recently by Whitcomb et al. (Science, N.Y., 180, 632; 1973), who showed that 4 years before the 1971 San Fernando earthquake of magnitude 6.4 the $v_{\mathrm{p}} / v_{\mathrm{s}}$ ratio decreased suddenly by $10 \%$ from its average value of 1.75 and then gradually rose back to about the average value at the time of the main event. Equally importantly, Whitcomb and his colleagues were able to propose a plausible physical mechanism for these changes in terms of rock dilatancy.

Whitcomb et al. also found that the greatest contribution to the change in $v_{\mathrm{p}} / v_{\mathrm{s}}$ occurred in $v_{\mathrm{p}}$ and thus argued that, because man-made explosions produce mainly $P$ waves, the path to earthquake prediction could be opened up by the use of artificial sources "such as large mine blasts" rather than being limited to the vagaries of earthquakes. This challenge was taken up by McEvilly and Johnson (Science, N.Y., 182, 581; 1973), who have examined the travel times of $\mathbf{P}$ waves from Californian quarry explosions of well known origin times. The results are disappointing to say the least. To put it bluntly, McEvilly and Johnson find no velocity changes associated with earthquakes at all.

The quarry at which the sixty-eight examined explosions occurred between July 12, 1961, and June 14, 1963, lies near Salinas, California. The $P$ waves from the blasts were recorded at the University of California's seismic stations, some of which have been in operation continuously since the early 1960 s and the nearest of which lies about $13 \mathrm{~km}$ from the quarry (equivalent to a $P_{g}$ wave travel time of $2.5 \mathrm{~s}$ ). The uncertainties in reading the $P$ wave arrival times were estimated to be less than $0.1 \mathrm{~s}$, although there were, of course, other possible sources of variation in travel times. For example, some of the blasts were not timed at the quarry, and their origin times had to be inferred to within $0.1 \mathrm{~s}$ on the basis of arrival times at the nearest station. But McEvilly and Johnson estimate that the maximum error possible, including that arising from a $10 \%$ dilatancy-induced velocity change over the distance to the nearest station, would give arrival times at a particular station within a range of $\pm 0.4 \mathrm{~s}$ about a mean value. Thus for mean travel times of $8.6-28.0 \mathrm{~s}$ to the seven stations used (excluding the nearest station), the extreme variations would be $\pm 5 \%$ at the nearer stations and $\pm 1.5 \%$ at the more distant stations. 